\title{
MARKETING SOCIAL CORPORATIVO E EMPREENDEDORISMO SOCIAL ${ }^{1}$ CORPORATIVE SOCIAL MARKETING AND ENTREPRENEURSHIP
}

\author{
Kerla Mattiello ${ }^{2}$ \\ Francisco Giovanni David Vieira ${ }^{3}$ \\ Isolde Terezinha Santos Previdelli ${ }^{4}$
}

\begin{abstract}
RESUMO: Este artigo é uma síntese dos resultados de um estudo que buscou evidenciar ações de marketing social corporativo (MSC) de grandes empresas brasileiras criadoras de institutos ou fundações empresariais. Buscou-se analisar e descrever programas de MSC e se as práticas decorrentes de tais programas influenciam a iniciativa de empreender institutos e fundações empresariais. Trata-se de fenômeno ainda inexplorado por pesquisadores de empreendedorismo e de marketing, o qual tem grande magnitude na sociedade brasileira contemporânea. Os procedimentos metodológicos adotados para o estudo envolveram a utilização de questionário como instrumento de coleta de dados por meio de pesquisa do tipo survey junto ao GIFE - Grupo Fundação, Institutos e Empresas, assim como envolveram a realização de análises estatísticas descritivas. Os resultados do estudo demonstram que embora práticas de MSC tenham ampliado ações sociais por parte das empresas e levado à criação de estruturas organizacionais elas não estão efetivamente alinhadas com ações de empreendedorismo social.
\end{abstract}

Palavras-chave: Marketing Social Corporativo, Empreendedorismo Social, Fundações.

ABSTRACT: This article is a synthesis of the results of a study that looked for evidencing actions of corporate social marketing (MSC) of large Brazilian companies that have created institutes and/or business foundations. It looked for to analyze and to describe programs of MSC and whether the current practices of such programs influence the initiative of undertaking institutes and business foundations. It is a phenomenon that is still unexplored by entrepreneurship and marketing researchers, which has great magnitude in the contemporary Brazilian society. The methodological procedures adopted for the study involved the use of questionnaire as instrument of collection of data through survey research that was applied to GIFE - Group of Foundation, Institutes and Companies, as well as involved the accomplishment of descriptive statistical analyses. The results of the study demonstrate that although practices of MSC have enlarged social actions by companies and have lead them to the creation of organizational structures, such practices are not indeed aligned with actions of social entrepreneurship.

Key words: Corporate Social marketing. Social Entrepreneurship. Institutes. Foundations.

\footnotetext{
${ }^{1}$ Artigo Recebido em 11.09.2008 . Revisado por pares em 29.11.2008 . Recomendado em 06.04.2009 por Denise Del Pra Netto Machado (editora). Publicado em 22.04.2009. Organização Responsável pelo periódico: Universidade regional de Blumenau - FURB - www.furb.br/rn
}

\footnotetext{
${ }^{2}$ Universidade Estadual de Maringá - UEM - kmattiello2@uem.br

${ }^{3}$ Universidade Estadual de Maringá - UEM - fgdvieira@uem.br

${ }^{4}$ Universidade Estadual de Maringá - UEM - itsprevidelli@uem.br
} 


\section{INTRODUÇÃO}

As discussões sobre ação social no Brasil e no mundo ganharam grande ênfase, principalmente a partir da última década. No que se refere à atuação social empresarial, o entendimento do fenômeno é tido como decorrência de um processo de globalização que trouxe consigo o rápido desenvolvimento tecnológico, o aumento da concorrência e a necessidade de diferenciação das empresas para conquistarem novas fatias do mercado e/ou manterem seus clientes. Tal situação traz, ainda, uma pressão internacional pela qualidade dos produtos e a fiscalização de práticas socialmente condenáveis, como o trabalho infantil e defesa e preservação ambiental, que influenciam sobremaneira as ações das empresas nacionais, especificamente aquelas interessadas no mercado externo (PIMENTA, SARAIVA e CORRÊA; 2006, p.214). Foi nesse contexto que começaram a acontecer as primeiras ações empresariais na área social, as quais visavam primeiramente o cumprimento de questões legais e posteriormente foram ampliadas às áreas de educação, saúde, meio ambiente, questões de gênero e culturais, entre outras (URDAN 2001, SCHROEDER e SCHROEDER 2004, TREVISAN 2002).

As ações sociais, assim, passaram a fazer parte do dia-a-dia das empresas e novos conceitos de marketing foram desenvolvidos, transformando em ganho para a empresa a boa repercussão destas ações. O Marketing Social Corporativo, abordado no presente trabalho, é entendido como uma maneira eficaz de construir a marca da empresa ou de seus produtos e serviços, reforçar, demonstrar e explicitar os valores corporativos, bem como atuar socialmente por meio de investimento corporativo na comunidade, visível especialmente por meio de programas de ações sociais de longo prazo, associados à marca da empresa (MASSÓ, 1998; PRINGLE e THOMPSON, 2000; OLIVEIRA, 2006).

A ação social empresarial através de um instituto ou fundação pode se configurar como uma estratégia de ação social empresarial, uma vez que a empresa pode definir ou auxiliar a definir o público-alvo interno ou externo a ser atendido de acordo com seu interesse de mercado e pode também fortalecer sua marca através da valorização do interesse social que a empresa demonstra na comunicação de seus produtos. Sob outra perspectiva, a ação de Marketing Social Corporativo pode não só acontecer através de um instituto ou fundação já existente, mas também levar a empresa a empreender uma nova organização do terceiro setor, que não possui finalidades lucrativas, mas com ações sociais alinhadas aos seus próprios interesses.

Ao partir para o campo do empreendedorismo, percebemos que tal ação se enquadra nos conceitos de empreendedorismo social, visto que o processo de empreender pode acontecer a partir da criação de produtos, a construção de uma organização e o fornecimento de respostas ao governo e à sociedade, bem como através da identificação de uma oportunidade de atuação junto aos problemas sociais encontrados (MELO NETO, 2002; HERNANDEZ, 1999; GARTNER, 1985; SHANE e VENKATARAMAN, 2000).

Tendo em vista esse cenário, o presente trabalho tem o objetivo de analisar a prática de marketing social corporativo como uma iniciativa para ações de empreendedorismo social, particularmente no que se refere à motivação de empresas nacionais empreenderem novas organizações para atuação social no terceiro setor. Para tanto, aspectos de ambas as teorias são explorados ao longo do trabalho, cujas análises empíricas são feitas tendo como base os dados de empresas cadastradas no GIFE - Grupo Fundação, Institutos e Empresas, o qual se caracteriza como a única plataforma brasileira com informações sobre a atuação empreendedora vinculada à criação de organizações do terceiro setor por parte de corporações que atuam no mercado brasileiro. 
Com relação à apresentação, o trabalho encontra-se dividido em cinco momentos: (i) marketing social corporativo e (ii) empreendedorismo social em que são discutidas bases teóricas do fenômeno observado; (iii) empreendedorismo e marketing social corporativo: evidências da realidade brasileira, onde são reunidas de forma convergente as contribuições teóricas dos campos do empreendedorismo e do marketing e ressaltadas as evidências empíricas do fenômeno observado no Brasil; (iv) procedimentos metodológicos, (iv) descrição e análise dos resultados e (v) conclusões, onde são assinaladas implicações gerenciais e teóricas do estudo, assim como limitações do estudo e sugestões para novas pesquisas.

\section{MARKETING SOCIAL CORPORATIVO}

A Teoria de Marketing teve grande desenvolvimento nos anos 60, época de grande desenvolvimento do capitalismo pós-guerras mundiais, auge da produção em massa advinda da industrialização crescente, momento em que administrativamente o foco passa a ser diferenciação dos produtos.

Em 1971, Kotler e Zaltman propõem o conceito de Marketing Social, que engloba a criação, implementação e controle de programas calculados para influenciar a aceitabilidade das idéias sociais e envolvendo considerações relativas ao planejamento de produto, preço, comunicação, distribuição e pesquisa de marketing (KOTLER; ZALTMAN, 1971, p.5). Sob esta perspectiva "o Marketing não deve ser associado somente aos bens físicos, mas também a serviços, pessoas, organizações e idéias" (OLIVEIRA, 2006, p. 56). A partir de então, diversos conceitos de Marketing surgem, como respostas a estudos que aplicam a Teoria de Marketing à questões sociais. Dentre estes conceitos está o Marketing Social Corporativo que trabalha o conceito de que o benefício da ação social deve ser mútuo; ou seja, a comunidade ganha e a empresa também ganha.

Para Massó (1998, p. 62), o objetivo do Marketing Social Corporativo é conquistar o "compromisso dos consumidores com um determinado comportamento de interesse social, favorecendo simultaneamente e de forma direta, a imagem da empresa e sua posição no mercado". Com esta proposta, o Marketing Social Corporativo, em detrimento dos demais conceitos de Marketing voltado a benefícios sociais, consegue abranger um grupo maior de interesse, os consumidores, funcionários e comunidade pela ação social em si e acionistas, governo e formadores de opinião, por meio do fortalecimento da marca pela vinculação à atuação em uma causa social (HIGUCHI e VIEIRA, 2008). Deve-se ter claro que o Marketing Social Corporativo envolve a Responsabilidade Social Corporativa, que envolve Projeto(s) Social(is), que envolve(m) Ação(ões) Social(is). 


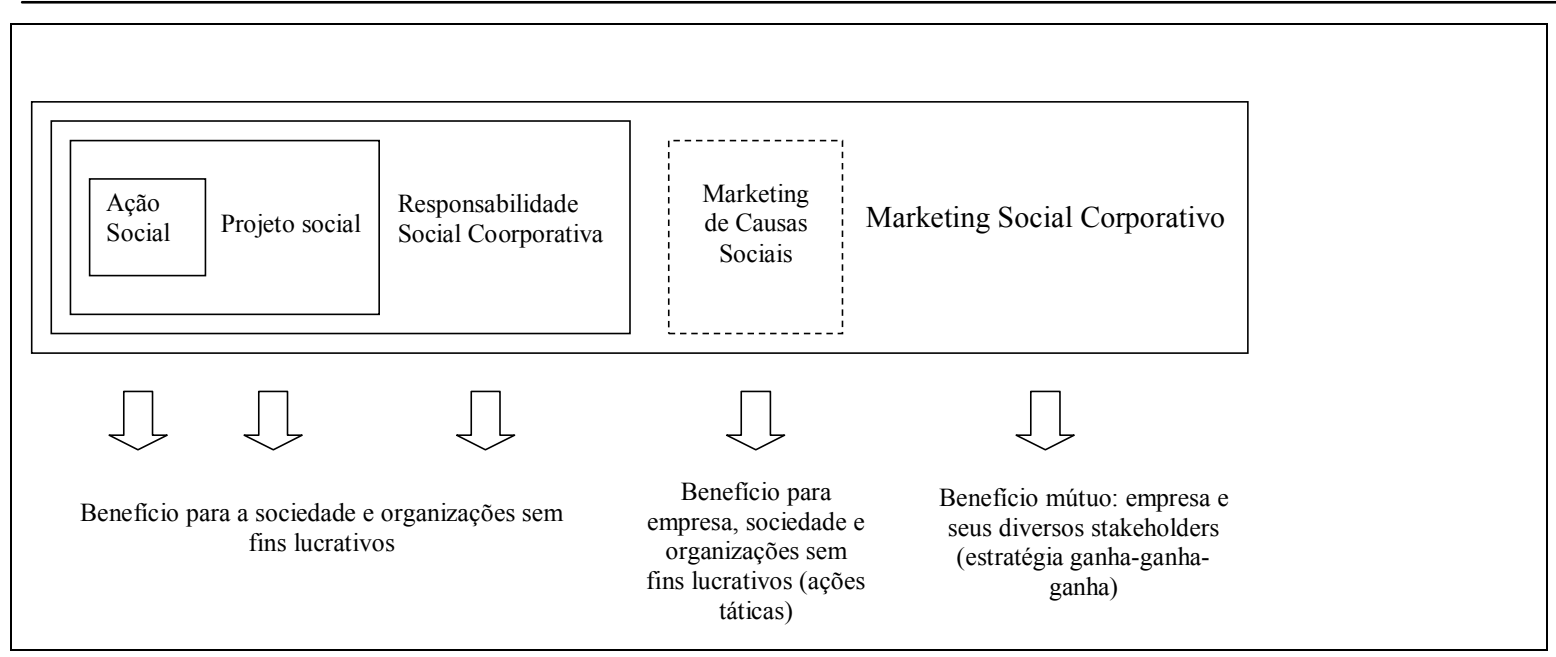

Figura 1: O Marketing Social Corporativo e suas conexões Fonte: Oliveira (2006).

De modo complementar, Massó (1998) indica que para obter os benefícios que o Marketing Social Corporativo oferece, a ação implica em uma relação estratégica de longo prazo, envolvendo valor social, causa selecionada, missão, cultura e estratégia corporativa.

Ainda, segundo Massó (1998), alguns pontos devem ser bem definidos quando do planejamento de um programa de MSC: beneficiar ao consumidor, ressaltar as vantagens, trocar para sobreviver, acordo prévio com o público, objetivo abordável, impacto suficiente, compromisso ético. Os conceitos e posicionamentos que a empresa pretende, devem ser cuidadosamente planejados para que não cause no consumidor a impressão de que a organização está com o intento de comprar uma atitude positiva em relação à marca ou produto, oferecendo ações sociais falsas. Todo este cuidado necessário pressupõe a intenção da empresa em conseguir, através de uma ação social, e da divulgação desta atividade aos grupos de interesse, a melhoria da sua imagem e um melhor relacionamento com seus clientes (VIEIRA et al., 2007).

\section{EMPREENDEDORISMO SOCIAL}

O termo empreendedor surgiu na França entre os séculos XVII e XVIII e era discutido por economistas. O economista mais associado ao termo foi Schumpeter e, nesse momento, o empreendedorismo era conceituado como uma ação voltada à criação de valor; sendo os empreendedores agentes econômicos inovadores que dirigem o processo criativodestrutivo do capitalismo, através da criação de novos mercados ou de novas formas para fazer coisas (MORT; WEERAWARDENA; CARNGIE, 2003). Schumpeter (1949 apud DORNELAS, 2001, p. 33) define o empreendedor como "capaz de quebrar a ordem corrente e inovar, criando mercado através de uma oportunidade identificada".

Para Dees (1998), o conceito de empreendedorismo pode ser aplicado tanto na área econômica como na área social e o termo empreendedorismo social pode até ser considerado novo, mas o fenômeno, não. No empreendedorismo social, o objetivo não é mais o negócio pelo negócio; trata-se, sim, do negócio do social, que tem na sociedade civil o seu principal foco de atuação e na parceria envolvendo comunidade, governo e setor privado, a sua estratégia (MELO NETO; FROES, 2002). Para Austin, Stevenson e Wei-Skillern (2006), os empreendedores econômicos e sociais têm as mesmas preocupações, embora, talvez, para graus variados, devido a diferenças na dinâmica de mercado entre os setores que atuam. Para os autores, o grau de diferença fundamental é pelo fato de que, no empreendedorismo 
econômico, o foco primário está nos lucros econômicos, enquanto no empreendedorismo social, o foco está nos lucros sociais (AUSTIN; STEVENSON; WEI-SKILLERN, 2006).

Em geral, o empreendimento social inicia-se com a percepção de um problema social e a busca de soluções - inovadoras ou já conhecidas -, seguindo a fase de teste da solução e sua implementação no público beneficiário ou na comunidade (ASHOKA, 2001). De acordo com Chell (2007), outro fator em comum entre o empreendedor social e o empreendedor econômico é que ambos conscientemente armazenam recursos alienáveis e usam o capital humano próprio para alcançar a sua missão, seja ela a riqueza ou a criação de valor social.

Como complementam Melo Neto e Froes (2002), o processo de empreendedorismo social exige, principalmente, o redesenho de relações entre comunidade, governo e setor privado, que se baseia no modelo de parcerias, tendo como principal objetivo retirar pessoas da situação de risco social e com o foco nos problemas sociais. O Quadro 1 apresenta as principais características do empreendedorismo privado, responsabilidade social empresarial e empreendedorismo social:

\begin{tabular}{|c|c|c|}
\hline $\begin{array}{l}\text { EMPREENDEDORISMO } \\
\text { PRIVADO }\end{array}$ & $\begin{array}{c}\text { RESPONSABILIDADE } \\
\text { SOCIAL } \\
\text { EMPRESARIAL }\end{array}$ & $\begin{array}{l}\text { EMPREENDEDORISMO } \\
\text { SOCIAL }\end{array}$ \\
\hline É individual & Individual com possíveis parcerias & É coletivo e integrado \\
\hline $\begin{array}{l}\text { Produz bens e serviços para o } \\
\text { mercado }\end{array}$ & $\begin{array}{l}\text { Produz bens e serviços para si e } \\
\text { para a comunidade }\end{array}$ & $\begin{array}{l}\text { Produz bens e serviços para a } \\
\text { comunidade, local e global }\end{array}$ \\
\hline Tem foco no mercado & $\begin{array}{l}\text { Tem o foco no mercado e atende a } \\
\text { comunidade conforme sua missão }\end{array}$ & $\begin{array}{l}\text { Tem o foco na busca de soluções } \\
\text { para os problemas sociais e } \\
\text { necessidades da comunidade }\end{array}$ \\
\hline $\begin{array}{l}\text { Sua medida de desempenho é o } \\
\text { lucro }\end{array}$ & $\begin{array}{l}\text { Sua medida de desempenho é o } \\
\text { retorno } \\
\text { aos envolvidos no processo } \\
\text { Stakeholders }\end{array}$ & $\begin{array}{l}\text { Sua medida de desempenho é o } \\
\text { impacto e a transformação social }\end{array}$ \\
\hline $\begin{array}{l}\text { Visa satisfazer necessidades dos } \\
\text { clientes e ampliar as } \\
\text { potencialidades do negócio }\end{array}$ & $\begin{array}{l}\text { Visa agregar valor estratégico ao } \\
\text { negócio e atender expectativas do } \\
\text { mercado e da percepção da } \\
\text { sociedade/consumidores. }\end{array}$ & $\begin{array}{l}\text { Visa resgatar pessoas da situação } \\
\text { de } \\
\text { risco social e promovê-las, gerar } \\
\text { capital social, inclusão e } \\
\text { emancipação social }\end{array}$ \\
\hline
\end{tabular}

Fonte: Oliveira (2004).

O empreendedorismo social é, antes de tudo, uma ação inovadora voltada para o campo social, um processo que se inicia com a observação de uma determinada situação ou problema local. Em seguida, procura-se elaborar uma alternativa para enfrentar esta situação (OLIVEIRA, 2004). Entre as inovações destas organizações sociais estão também o desenvolvimento de formas e alternativas de aproximação inovadoras para obter renda (AUSTIN; STEVENSON; WEI-SKILLERN, 2006).

Sob outro aspecto, Ozgen e Baron (2006) comentam que o reconhecimento de oportunidade constitui aspecto chave do processo empreendedor e, de fato, é visto como o primeiro passo através do qual fluem outras fases do processo de criação de um novo empreendimento. No empreendedorismo social, a oportunidade é tida como áreas de preocupação social e políticas públicas relacionadas àquela área de preocupação social (MORT; WEERAWARDENA; CARNGIE, 2003). Diante da oportunidade, "o empreendedor deve avaliar o que tem em mãos, para evitar despender tempo e recursos em uma idéia que talvez não agregue tanto valor" (DORNELAS 2001, p. 56). 


\section{POSSIBILIDADES TEÓRICAS DE MARKETING SOCIAL CORPORATIVO E EMPREENDEDORISMO SOCIAL}

As empresas, ao executarem suas atividades, devem seguir leis e normas que regulamentam sua interferência no meio ambiente, sua relação com os funcionários, sua interação com o governo e outras empresas (OLIVEIRA, 2006). Entretanto, seguir estas regras não representa uma fonte de vantagem competitiva. A vantagem pode ser conseguida se a empresa for além das regulamentações legais do pagamento de impostos e do objetivo de gerar lucro, e apresentar atitudes éticas e relacionadas a marketing social corporativo, que beneficiem o ambiente e a coletividade com quem a empresa se relaciona (PRINGLE; THOMPSON, 2000).

De acordo com Austin (2001 apud SALAZAR; DORIZOTTO, 2005), existem três estágios possíveis (Continuum da colaboração) de se identificar em uma parceria entre o Segundo Setor (a empresa) e o Terceiro Setor e a distinção de um estágio para o outro se faz de acordo com o grau de interação, importância estratégica e envolvimento administrativo das partes: estágio Filantrópico; estágio Transacional e estágio Integrativo.

O interessante, segundo este estudo, é quando parceria atinge o terceiro estágio, operando-se a integração das duas organizações, aumentando ainda mais a identificação entre elas e a estabilidade da receita para a instituição. Esta parceria tem um importante valor estratégico para a empresa e um grande grau de interação, como pode ser notado no Quadro 2:

\begin{tabular}{|c|c|c|c|}
\hline $\begin{array}{c}\text { Estágio do } \\
\text { relacionamento }\end{array}$ & $\begin{array}{c}\text { Um } \\
\text { Filantrópico } \rightarrow\end{array}$ & $\begin{array}{c}\text { Dois } \\
\text { Transacional } \rightarrow\end{array}$ & $\begin{array}{c}\text { Três } \\
\text { Integrativo }\end{array}$ \\
\hline Nível de envolvimento & Fraco $\rightarrow \rightarrow \rightarrow \rightarrow \rightarrow$ & $\rightarrow \rightarrow \rightarrow \rightarrow \rightarrow \rightarrow$ & $\rightarrow \rightarrow$ Intenso \\
\hline $\begin{array}{l}\text { Importância para a } \\
\text { missão }\end{array}$ & Periférica $\rightarrow \longrightarrow \rightarrow$ & $\rightarrow \rightarrow \longrightarrow \rightarrow \rightarrow \longrightarrow$ & $\rightarrow \rightarrow$ Estratégica \\
\hline $\begin{array}{l}\text { Magnitude dos } \\
\text { recursos }\end{array}$ & Pequena $\rightarrow \longrightarrow \rightarrow \longrightarrow$ & $\rightarrow \rightarrow \longrightarrow \rightarrow \longrightarrow \rightarrow$ & $\rightarrow \rightarrow$ Grande \\
\hline Âmbito das atividades & Estreito $\rightarrow \longrightarrow \rightarrow \longrightarrow$ & $\rightarrow \rightarrow \rightarrow \rightarrow \rightarrow \longrightarrow$ & $\rightarrow \rightarrow$ Amplo \\
\hline Grau de interação & Esporádico $\rightarrow \longrightarrow$ & $\rightarrow \rightarrow \rightarrow \rightarrow \rightarrow \rightarrow$ & $\rightarrow \rightarrow$ Intenso \\
\hline $\begin{array}{l}\text { Complexidade } \\
\text { administrativa }\end{array}$ & Simples $\rightarrow \rightarrow \rightarrow$ & $\rightarrow \rightarrow \rightarrow \rightarrow \rightarrow \rightarrow$ & $\rightarrow \rightarrow$ Complexa \\
\hline Valor estratégico & Modesto $\rightarrow \rightarrow \longrightarrow$ & $\rightarrow \rightarrow \rightarrow \rightarrow \rightarrow \rightarrow$ & $\rightarrow \rightarrow$ Importante \\
\hline
\end{tabular}

Quadro 2: Continuum da colaboração

Fonte: Austin (2001 apud SALAZAR; DORIZOTTO, 2005).

Em consonância com estes estágios de parceria, a teoria de MSC define também que, para a melhor abrangência dos projetos, conforme já citado por Massó (1997): a) ampliação dos alvos empresariais; b) não se tratar de simples filantropia, mas sim em destinar esforços para a colaboração com uma causa de interesse social para compartilhar valores; c) cooperação com entidades, em um plano de igualdade, uma vez que a empresa doa recursos e horas de trabalho a fundo perdido; d) as ações devem ser realizadas de forma contínua; e) as empresas e entidades sem fins lucrativos podem beneficiar-se mutuamente; f) a possibilidade de uma ação contínua e estratégica de longo prazo, envolvendo valor social, causa selecionada, missão, cultura e estratégia corporativa.

Ainda quanto à identificação de oportunidades, dentre as oito fórmulas descritas por Degen (1989), podemos transferir ao MSC a possibilidade de utilização direta de cinco destas fórmulas, no contexto social, sendo elas: 1) a identificação de necessidades sociais que reivindicam ação; 2) observação de deficiências, ou seja, dentro do segmento desejado cabe ao empreendedor identificar as deficiências e agregar valor que os consumidores estejam 
dispostos a pagar; 3) observação de tendências que ocasionam mudanças, podendo trazer novas oportunidades de atuação social; 4) procura de soluções sociais e desenvolvimento de ações para a resolução dos problemas sociais. Estas fórmulas são justificadas pela teoria de MSC, através do exercício das ações sociais, mostrando à sociedade seu compromisso duradouro com a difusão de determinados valores e a resolução de problemas sociais que preocupam seus clientes (OLIVEIRA, 2006; HIGUCHI e VIEIRA, 2007). Complementando, há ainda indiretamente a utilização de: 5) derivação da ocupação atual; 6) lançamento de moda, ou aplicação de buscar idéias originais que possam encantar grande número de consumidores, contudo, nem sempre é uma idéia original, mas apenas alguma idéia que ainda não foi aplicada a um determinado mercado; e 7) imitação de sucesso alheio.

A justificativa vem de Massó (1998), que explica que deve existir harmonia entre o valor social eleito, a causa selecionada, a missão e a cultura corporativa, integrando estes programas na estratégia global da empresa. A causa eleita deve, preferencialmente, ter relação com a atividade da empresa ou com o seu público alvo. Este fato justifica o alinhamento encontrado pelo levantamento do GIFE (2006) e que apresentou que, entre todos os institutos e fundações cadastrados, em $45,5 \%$ deles existem programas ou projetos voltados de forma exclusiva ou preferencial para funcionários da empresa mantenedora (GIFE, online, 2006). Não há levantamento com relação a clientes. De acordo com o mesmo levantamento, um número significativo de Institutos e Fundações procura atender às demandas do entorno em que estão.

Outro fator que colabora para a possibilidade gerencial do MSC ser visto como uma atividade que pode influenciar o empreendedorismo social por empresas é resultado do estudo de Rossoni, Onozato e Horochovski (2006), que avaliou os resultados encontrados nos indicadores do GEM sobre a atividade empreendedora de uma forma geral com a atividade empreendedora social. Este fator demonstra um perfil que pode ser de diretores de grandes empresas atuantes em programas de MSC com um grande envolvimento, justificando, conforme Massó (1998), que a obtenção de maiores e melhores resultados de um programa da MSC para todos os interessados está vinculado ao nível de envolvimento direto da empresa, não somente com o auxílio financeiro à causa, mas um compromisso verdadeiro, incluindo funcionários, diretores e fornecedores.

O processo de construção e posicionamento de marcas empresariais, de produtos ou serviços, que ocorre em programas de marketing social corporativo contempla uma interface com o campo do empreendedorismo social, quando empresas/corporações decidem implementar ações empreendedoras de caráter social, criando fundações e/ou institutos para atuação no terceiro setor, vinculados a uma determinada causa social (MATTIELLO e VIEIRA, 2008). Isso indica que é possível construir a marca de uma empresa ou de seus produtos e serviços, reforçar, demonstrar e explicitar valores corporativos, ao mesmo tempo em que se atua socialmente através de investimento corporativo na comunidade, de modo visível e responsável, especialmente por meio de programas de ações sociais de longo prazo (CORREA e VIEIRA, 2008). Por outro lado, do ponto de vista teórico, indica que empreendedorismo social e marketing social corporativo possuem construtos que são próximos e que reivindicam atenção analítica e construção teórica multidisciplinar.

\section{PROCEDIMENTOS METODOLÓGICOS}

Este estudo caracterizou-se como analítico-descritivo, uma vez que buscou, a partir de uma análise preliminar, descrever evidências empíricas encontradas acerca da existência e desenvolvimento de ações sociais realizadas por institutos e fundações empresariais, as quais se caracterizem como marketing social corporativo (BECKER, 1997). 
O universo da pesquisa foi composto pelas fundações e institutos associados ao GIFE, cujo cadastro foi disponibilizado no site da organização. A escolha do GIFE como base para a realização da pesquisa se deveu ao fato de ser a única organização brasileira a congregar, de forma organizada e sistematizada, empresas que possuem fundações e institutos voltados para o desenvolvimento de ações de caráter social. Na base do GIFE, em 2007, foram identificadas 112 organizações cadastradas, sendo 42 fundações, 38 associações e institutos e 32 empresas que praticam ações sociais. As organizações foram analisadas e ao final da análise foram selecionadas 68 organizações que criaram institutos ou fundações.

Como instrumento de coleta de dados foi empregado o questionário auto-aplicado com perguntas estruturadas. As questões foram formuladas, em sua maior parte, utilizando-se escala do tipo Likert, ao longo de um continuum com cinco postos, em ordem de importância, variando de "nenhum" a "totalmente", as quais já estavam disponíveis e foram anteriormente empregadas em estudo de marketing social corporativo por Oliveira (2006). O critério utilizado para mensurar a validade das escalas foi o teste Alpha de Cronbach, que obteve um índice de 0,93, sendo que segundo Malhotra (2006), os índices de coeficiente de Alpha superiores a 0,6 podem ser considerados válidos.

Os questionários foram encaminhados por correio eletrônico e as respostas puderam ser encaminhadas através de e-mail. Uma outra forma para a obtenção de resposta foi providenciada através de questionário online disponibilizado em endereço eletrônico por meio da World Wide Web. O número de questionários que retornou foi de 36 , o que equivale a $52,9 \%$ dos questionários enviados. Quanto ao retorno dos questionários, tanto Mangione (1997) quanto Günter (2003) citam que esse percentual de retorno pode ser considerado representativo. Selltiz et al. (1975), por outro lado, estimam que este número varie entre 10\% e 50\%, enquanto Cooper e Schindler (2003) sugerem taxas de retorno em torno de 30\%, afirmando que este número pode chegar a $70 \%$.

Após a tabulação dos dados as análises estatísticas foram realizadas por meio do software Statistica. Para a efetivação da análise utilizou-se a estatística não-paramétrica, que, de acordo com Siegel (2006, p.54), "tipicamente fazem menos suposições sobre os dados e podem ser mais relevantes para uma situação em particular". O coeficiente de correlação adotado foi o de Spearman, o qual foi empregado com o intuito de verificar a existência de co-relacionamento ou correspondência entre variáveis (BABBIE, 1999; KIRSTEN, 1980). O nível de significância calculado foi de $95 \%$ ( $p>0,05)$.

Como critérios para reforçar a credibilidade e validade da pesquisa, os dados obtidos junto às empresas foram não só confirmados com as próprias empresas, como também foram confirmados e cruzados com a base de dados do GIFE. Posteriormente, foi realizada uma confirmação adicional, junto ao instituto ou fundação envolvida, configurando, assim, uma triangulação dos dados, técnica mencionada tanto por Alencar (1999) quanto por AlvesMazzotti e Gewandsznajder (2002), para a validação e confirmação da fidedignidade de dados obtidos em pesquisa nas ciências sociais aplicadas, além de representar a busca de diferentes maneiras para se investigar um mesmo fenômeno social.

\section{DESCRIÇÃO E ANÁLISE DOS RESULTADOS}

As empresas pesquisadas, em sua maioria, já atuam no mercado brasileiro há mais de 50 anos, sendo estas 56\%. Entre as empresas que atuam há menos de 20 anos, metade delas atua na área de telefonia móvel. A grande maioria $(85 \%)$ já realiza ações sociais há mais de 10 anos, e $15 \%$ delas definiram que realizam ações sociais pelo período compreendido entre 5 e 10 anos. Nenhuma das empresas pesquisadas realiza ações sociais há menos de 5 anos, 
demonstrando que mesmo entre as empresas mais novas já existe a prática de ações sociais, iniciada em data muito próxima a da criação da empresa e que estas ações são contínuas.

Para a identificação das empresas que praticam Marketing Social Corporativo adotouse como pressuposto que se as empresas divulgam suas ações de responsabilidade social, elas estão confirmando que o marketing social corporativo implica na responsabilidade social em uma perspectiva de marketing para fortalecer a marca perante o consumidor, o que envolve o presente estudo. Entre as empresas estudadas, apenas 3\% das empresas afirmaram que não divulgam as ações sociais, ou não possuem as ações sociais incorporadas à comunicação da empresa. A grande maioria utiliza o portal de empresa na Internet para divulgar as ações sociais. Dentre as características que identificam a prática do Marketing Social Corporativo como: valorização da marca; benefício social; benefícios para a empresa; ações contínuas; direcionamento de recursos; envolvimento entre causa selecionada, missão, valor social e estratégia e causa escolhida corresponde às competências empresariais; a pesquisa de campo identificou os resultados apresentados a seguir.

Quanto à escolha da causa, 85\% das empresas afirmaram que a causa escolhida está bastante ou totalmente em consonância com a missão da empresa. Um total de $83 \%$ das empresas entrevistadas respondeu que o fator que levou à escolha da causa e que influenciou tal escolha foi a identificação de necessidades da comunidade. Para 75\% das empresas a causa escolhida apresenta bastante significado para os valores da marca da empresa. Ainda que todas as afirmações sobre a causa tenham alcançado resultados significativos, mais de $50 \%$ das respostas classificadas como totalmente ou bastante influentes para a escolha da causa, os motivos elencados como mais importantes pelas empresas que responderam esta pesquisa estão em concordância com o que Massó (1998) define como pontos importantes para a prática do MSC. Segundo ou autor, deve existir harmonia entre o valor social eleito, a causa selecionada, a missão e a cultura corporativa, integrando estes programas na estratégia global da empresa.

Os resultados sobre a visão da empresa quanto as principais mudanças após a criação do Instituto ou Fundação estão relacionados à melhoria das ações da empresa com a comunidade e o desenvolvimento do valor social empresarial com $87 \%$ e $82 \%$ na soma das respostas totalmente e bastante (consideradas na escala adotada, já mencionada na seção anterior deste artigo). Os próximos elementos avaliados como importantes avanços após a criação do Instituto ou Fundação referem-se à contribuição na definição de uma identidade para a empresa e o fortalecimento da marca da empresa ou de seus produtos, com $79 \%$ e $72 \%$ das respostas, somados os escores obtidos nas respostas totalmente e bastante. Todos estes benefícios são citados por Oliveira (2006) e por Massó (1998) como resultados de um posicionamento estratégico adotado pela empresa e do cuidado no desenvolvimento do programa de MSC envolvendo valor social, causa selecionada, missão, cultura e estratégia corporativa. A visão da empresa após a criação do Instituto ou Fundação está apresentada na Tabela 1.

Tabela 1: A visão da empresa após a criação do Instituto ou Fundação

\begin{tabular}{|c|c|c|c|c|c|}
\hline \multirow{2}{*}{ Visão da Empresa } & Não & Pouco & Medianamente & Bastante & Totalmente \\
\hline & $\%$ & $\%$ & $\%$ & $\%$ & $\%$ \\
\hline $\begin{array}{l}\text { Melhora a ação da empresa com a } \\
\text { comunidade }\end{array}$ & - & 3 & 10 & 39 & 48 \\
\hline $\begin{array}{l}\text { Atende algumas comunidades no entorno da } \\
\text { empresa }\end{array}$ & 6 & 21 & 6 & 39 & 27 \\
\hline $\begin{array}{l}\text { Fortalece a marca da empresa ou a marca dos } \\
\text { seus produtos }\end{array}$ & 3 & 9 & 16 & 47 & 25 \\
\hline Contribui para definir uma identidade da & 3 & 9 & 9 & 61 & 18 \\
\hline
\end{tabular}

Revista de Negócios, ISSN 1980-4431, Blumenau, v. 13, n. 4 p. 72 - 88, Outubro/Dezembro 2008. 
empresa

A realização de ações sociais gera oportunidade de negócios

Foi motivada por interesses políticos Melhora a identidade corporativa da empresa

Auxilia a alcançar os objetivos estratégicos da empresa

Desenvolve valor social empresarial

Atende apelos de campanhas públicas

(enchentes, fome, etc.)

Aumenta a satisfação dos empregados da empresa

Complementa ações do governo

Aumenta o faturamento da empresa

Atende solicitações de outras entidades

(governamentais, ou comunitárias)

Facilita o processo sucessório dentro da empresa

Representa uma oportunidade para a atuação empresarial na área social

Fonte: Pesquisa de campo, 2008.

$\begin{array}{ccccc}25 & 28 & 22 & 16 & 9 \\ 85 & 9 & 3 & - & 3 \\ 19 & - & 16 & 47 & 19 \\ 13 & 29 & 19 & 23 & 16 \\ 3 & 3 & 12 & 50 & 32 \\ 45 & 24 & 12 & 9 & 9 \\ 3 & 3 & 26 & 53 & 15 \\ 3 & 3 & 24 & 42 & 27 \\ 69 & 16 & 6 & 6 & 3 \\ 12 & 30 & 27 & 21 & 9 \\ 72 & 9 & 9 & 3 & 6 \\ 9 & 9 & 9 & 26 & 49\end{array}$

Entre os resultados que não foram considerados ou pouco considerados na avaliação das empresas pesquisadas, estão a motivação por interesses políticos com $94 \%$ das respostas, e o aumento do faturamento da empresa com $85 \%$ das respostas, sendo ainda que este último pode ter obtido tal índice pela dificuldade encontrada em mensurar os resultados obtidos através das ações sociais (AUSTIN; STEVENSON; WEI-SKILLERN, 2006).

Por outro lado, particularmente no que se refere aos benefícios conseguidos pela empresa após a criação da organização para atuar com ações sociais, o principal destaque concerne à melhoria da relação da empresa com a comunidade externa, com $86 \%$ das respostas avaliadas positivamente (totalmente ou bastante). Outros aspectos que receberam destaque dizem respeito ao aumento da vinculação da empresa com a comunidade externa $(83 \%)$ e a melhora da imagem corporativa (80\%). Estas informações estão apresentadas na Tabela 2, que demonstra, também, o pouco impacto das ações sociais em termos mercadológicos, especificamente com nenhuma ou pouca alteração no volume de vendas e na participação da empresa no mercado (67\% e 69\%, respectivamente).

Tabela 2: Benefícios empresariais após a criação do Instituto ou Fundação

\begin{tabular}{|c|c|c|c|c|c|}
\hline \multirow{2}{*}{ Visão da Empresa } & Não & Pouco & Medianamente & Bastante & Totalmente \\
\hline & $\%$ & $\%$ & $\%$ & $\%$ & $\%$ \\
\hline Alteração no volume de vendas & 56 & 11 & 19 & 11 & 4 \\
\hline $\begin{array}{l}\text { Aumento da participação da empresa no } \\
\text { mercado }\end{array}$ & 54 & 15 & 12 & 15 & 4 \\
\hline $\begin{array}{l}\text { Valorização da empresa na sociedade e no } \\
\text { mercado }\end{array}$ & 11 & 7 & 29 & 39 & 14 \\
\hline $\begin{array}{l}\text { Fortalecimento e fidelidade à marca por parte } \\
\text { dos consumidores }\end{array}$ & 26 & 22 & 22 & 26 & 4 \\
\hline $\begin{array}{l}\text { Criação de vínculos de fidelização do } \\
\text { consumidor }\end{array}$ & 26 & 15 & 41 & 19 & - \\
\hline Captação de novos clientes & 27 & 23 & 23 & 19 & 8 \\
\hline $\begin{array}{l}\text { Aumento na vinculação da empresa com a } \\
\text { comunidade externa }\end{array}$ & - & 3 & 14 & 48 & 34 \\
\hline $\begin{array}{l}\text { Maior produtividade através do empenho e } \\
\text { motivação dos funcionários }\end{array}$ & 14 & 21 & 31 & 21 & 11 \\
\hline Melhora na imagem corporativa & - & 7 & 13 & 50 & 30 \\
\hline
\end{tabular}

Revista de Negócios, ISSN 1980-4431, Blumenau, v. 13, n. 4 p. 72 - 88, Outubro/Dezembro 2008. 
Retenção e atração de talentos

Atração de investidores

Melhora no padrão das relações da empresa com seus empregados

Melhora no padrão das relações da empresa com seus fornecedores

Melhora no padrão das relações da empresa com seus clientes

Melhora no padrão das relações da empresa com a comunidade externa

Melhora no ambiente organizacional $\begin{array}{lllll}14 & 11 & 32 & 36 & 7\end{array}$

$35 \quad 12$

$7 \quad 17$

17

31

37

15

31

45

Quanto às análises estatísticas, um destaque importante deve ser dado à correlação entre as variáveis alteração do volume de vendas e aumento da participação no mercado com 0,98 de associação e as variáveis fortalecimento e fidelidade à marca por parte dos consumidores e a variável criação de vínculos de fidelização do consumidor com 0,89 de associação. As associações com menores índices foram as relacionadas à comunidade externa, especificamente aumento da vinculação da empresa com a comunidade externa e melhora no padrão das relações da empresa com a comunidade externa. Verificou-se também que há uma considerável correlação entre a variável ações sociais incorporadas à comunicação de empresa e as variáveis fortalecimento e fidelidade à marca por parte dos consumidores, criação de vínculos de fidelização do consumidor, maior produtividade através do empenho e motivação dos funcionários e melhora no padrão das relações da empresa com seus clientes.

As variáveis identificadas para a caracterização do empreendedorismo social foram: inovação; riscos; exploração de oportunidade; parceria com governo, comunidade e setor privado; busca de lucros sociais; percepção de problemas sociais; busca de soluções sociais e ação coletiva e integrada.

Quanto à criação do Instituto ou Fundação, 67\% das empresas pesquisadas informaram que a criação do Instituto ou Fundação partiu da presidência da empresa e 18\% informaram que partiu da diretoria da empresa. De acordo com Rossoni, Onozato e Horochovski (2006) este perfil do empreendedor social também foi encontrado no levantamento efetuado pelo GEM que aponta pessoas de renda familiar alta, com alta escolaridade e predominantemente do sexo masculino. Além do fato de este empreendedor não ter tanta necessidade de se preocupar com aspectos relacionados ao atendimento de suas necessidades básicas, e ainda contam com recursos intelectuais e habilidades de liderança para desenvolver tais empreendimentos (ROSSONI; ONOZATO; HOROCHOVSKI, 2006). Em apenas 6\% das empresas a criação do Instituto ou Fundação ocorreu de maneira coletiva e em $3 \%$ houve a integração de vários níveis da empresa. Para Melo Neto e Froes (2002) e Oliveira (2006), o empreendedorismo social ocorre de maneira coletiva e integrada, agregando valor social através das diversas parcerias.

Sobre a participação dos diversos níveis hierárquicos da empresa com as atividades do Instituto ou Fundação, o maior envolvimento é da presidência apresentando como totalmente envolvido e bastante envolvido $88 \%$ dos respondentes. Na seqüência, a diretoria é apresentada como totalmente envolvida e bastante envolvida em $76 \%$ das empresas entrevistadas. A participação da gerência e funcionários se apresenta de maneira semelhante quanto aos percentuais de participação. Em 29\% das empresas pesquisadas não há participação de familiares dos empregados, gerentes, diretores e presidente nas atividades do Instituto ou Fundação, e em 41\% das empresas é pouca a participação deste grupo.

Quando questionadas quanto à semelhança entre as ações que eram realizadas pela empresa antes da criação do Instituto ou Fundação e as ações desenvolvidas pelo Instituto ou Fundação criados, $46 \%$ das empresas responderam que sim, ou seja, que há semelhanças. 
Porém, consideram as ações mais abrangentes. De modo complementar, 11\% responderam que as ações do Instituto ou Fundação são complementares às ações desenvolvidas anteriormente pelas empresas. Apenas 3\% afirmaram que as ações são as mesmas. Por outro lado, $40 \%$ das empresas pesquisadas responderam que as ações não são semelhantes, afirmando, assim, que houve uma inovação nas ações sociais empresariais quando da criação do Instituto ou Fundação.

Dentre os motivos mais importantes que levaram as empresas pesquisadas a criar um Instituto ou Fundação estão identificação de necessidades sociais, com $71 \%$ das respostas, observação de tendências sociais, com 50\% das respostas, e outros motivos, com $67 \%$ das respostas. Os outros motivos apresentados, foram descritos como: resultado de um estudo de cenário, necessidade de aumento do nível de escolaridade dos funcionários, benefícios sociais para os funcionários e disseminação de Know-how desenvolvido pela empresa, relacionado a temas ambientais.

Entre os temas de menor importância para a criação do Instituto ou Fundação estão: procura de soluções sociais e resolução de problemas sociais (50\%), derivação da ocupação atual (47\%), observação de deficiências sociais (45\%), e aplicação de uma idéia social original (43\%), conforme apresentado no Gráfico 1:

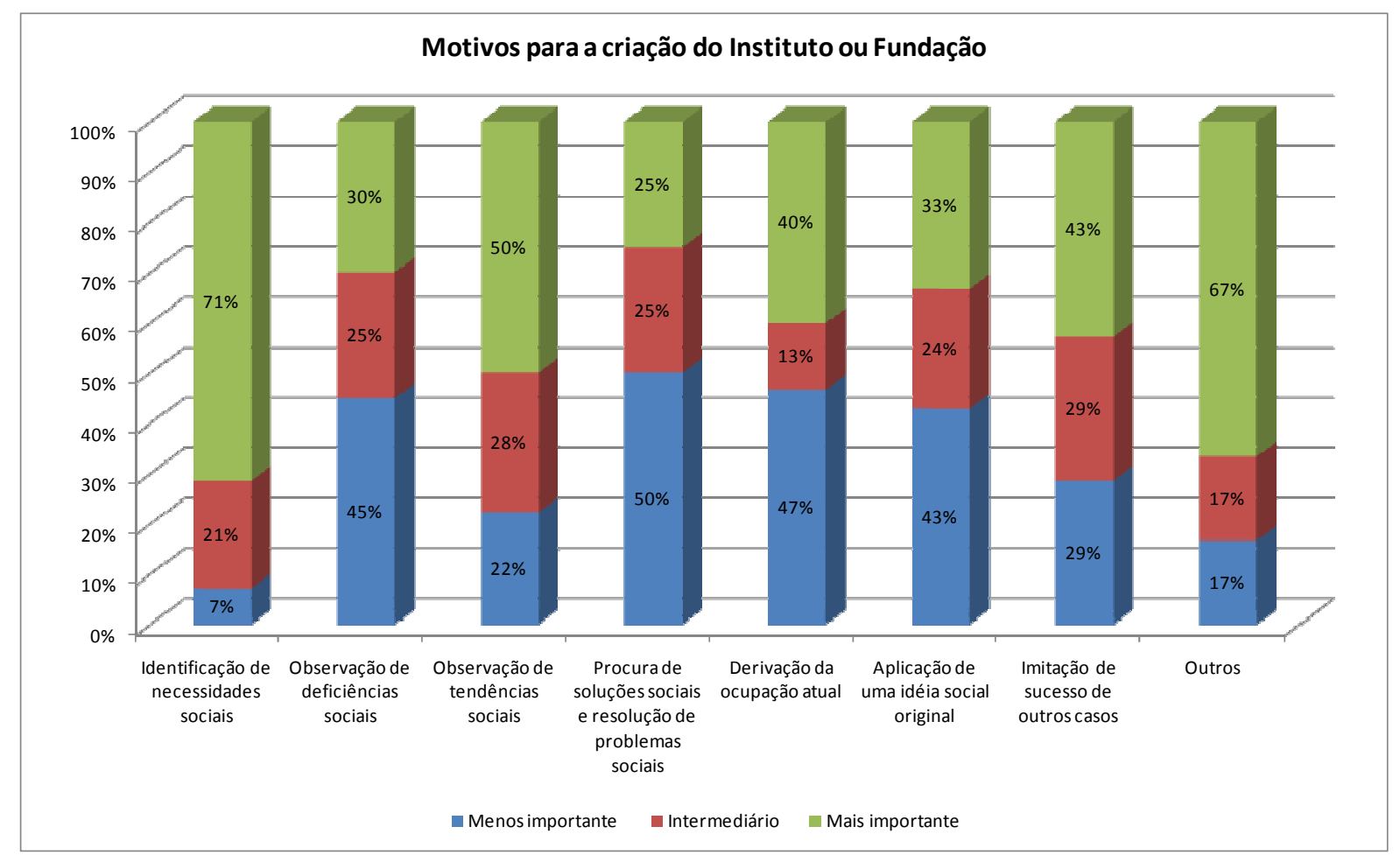

Gráfico 1: Motivos para a criação do Instituto ou Fundação

Fonte: Pesquisa de campo (2008)

Os motivos apresentados estão baseados nas 7 fórmulas de Degen (1989) e representam a identificação de oportunidades para a atuação social. Um aspecto relevante a ser observado consiste do motivo mais importante e o menos importante apresentado: a identificação de necessidades sociais, como mais importante segundo a visão das empresas criadoras, e a procura de soluções sociais e resolução de problemas sociais, como o menos importante. Segundo Mort, Weerawardena e Carngie (2003), Austin, Stevenson e WeiSkillern (2006) e Ozgen e Baron (2006), ainda que o foco dos empreendimentos sociais seja o lucro social e a resolução de problemas sociais, o reconhecimento de oportunidade de atuação se dá através da identificação de necessidades sociais. Posteriormente, a exploração da 
oportunidade social implicará na resolução de problemas sociais, o que pode explicar este último como sendo menos importante no momento de criação do Instituto ou Fundação empresarial. O primeiro passo para o empreendimento social é o reconhecimento de uma oportunidade social, e só posteriormente ocorrem as fases de busca de soluções, teste da solução e implementação (OZGEN, BARON; 2006).

A análise de correlação entre as respostas obtidas quanto ao motivo para a criação do instituto ou fundação demonstrou que houve uma correlação altamente significativa, com índice de 0,93 entre as respostas derivação da ocupação atual e imitação de sucesso de outros casos. Este índice demonstra que houve uma forte convergência entre as respostas citadas. Outras correlações não muito significativas, mas consideráveis, ocorreram entre as respostas identificação de necessidades sociais, derivação da ocupação atual, observação de tendências sociais e imitação de sucesso de outros casos.

Outro aspecto relacionado ao empreendimento é o risco que se corre com a criação de uma nova organização. Dentre as empresas pesquisadas, um total de $88 \%$ afirmou que não correram riscos com a criação do Instituto ou Fundação. Uma das empresas que respondeu ter corrido riscos com a criação do Instituto ou Fundação afirmou que o risco estava relacionado à maior visibilidade, necessidade de coerência entre discurso e prática e obrigatoriedade de transparência por se tratar de uma Oscip (Organização Social e Civil de Interesse Público) fiscalizada pelo Ministério Público. Outra empresa enfatizou que o risco ocorreu pela opção da empresa em investir um recurso significativo na criação de uma instituição com foco bem definido, conservação da natureza, em uma época em que as questões ambientais não estavam tão emergentes e a responsabilidade social empresarial não era considerada um diferencial no mercado. Segundo Davidson (2005) correr riscos é um assunto inerente ao empreendedorismo. O empreendedor social também está sujeito aos riscos financeiros, psicológicos e sociais demonstrados neste estudo pelas respostas de duas empresas que afirmaram ter corrido riscos.

\section{CONCLUSÃO}

Este estudo revela, como fruto de uma interface teórica entre marketing social corporativo e empreendedorismo social, que a ação de marketing social corporativo pode levar à iniciativa de criação de uma organização para atuação no terceiro setor, sendo esta um instituto ou fundação. Ao investigar esse pressuposto, a pesquisa de campo que subsidiou este artigo demonstrou a existência de aspectos administrativos e mercadológicos que sinalizam a prática de marketing social corporativo por parte de empresas brasileiras associadas ao GIFE.

Não obstante, tal prática não seja implementada em todo o seu potencial, ela se tem se manifestado por meio da criação de institutos ou fundações empresariais no Brasil e tem resultado, em última instância, no fortalecimento da marca das empresas ou de seus produtos. Conforme os resultados obtidos com a pesquisa, essa é visão tida e a avaliação compartilhada pelas próprias empresas que emprenderam as referidas organizações.

Uma importante contradição ou lacuna, entretanto, foi encontrada ao longo da condução desse estudo, particularmente quanto à forma de criação dos institutos e fundações, que não apresentam várias das características relacionadas ao empreendedorismo social. Esse é o caso observado em que, por exemplo, as ações sociais identificadas geram resultados para a sociedade, porém outros aspectos inerentes ao empreendedorismo social, como vinculação à necessidade de coletividade e existência de riscos, não estão presentes e, por conseguinte, não são congruentes com construtos teóricos de emprendedorismo social. Desse modo, os resultados demonstram que as características envolvidas na criação do instituto ou fundação, 
por parte da empresas, estão mais próximas das características de empreendedorismo econômico e responsabilidade social e que, portanto, as ações desenvolvidas resultam de uma ampliação das ações sociais dessas empresas por meio de uma organização sem fins lucrativos, criada não por uma ação coletiva e integrada da sociedade, mas sim por uma estratégia cuja lógica é preponderantemente empresarial.

Em curtas palavras, as características assinaladas pelas empresas para a criação dos institutos e fundações demonstram que esse empreendedorismo não pode ser totalmente qualificado como empreendedorismo social e, consequentemente, ainda que as práticas de marketing social corporativo tenham influenciado a ampliação das ações sociais por meio da criação de uma estrutura organizacional do terceiro setor, não podemos afirmar que as ações de marketing social corporativo desenvolvidas estejam alinhadas com ações de empreendedorismo social nas empresas estudadas.

\section{Implicações gerencias e teóricas}

As empresas participantes da pesquisa demonstraram uma tendência muito forte quanto à prática de marketing social corporativo voltada à comunidade do entorno da empresa e aos funcionários de empresa. Esta tendência também foi encontrada por outros estudos, o que demonstra que a utilização e os resultados desta prática estão aquém do que é sugerido em construções teóricas sobre o tema. Para o alcance de melhores resultados para a empresa, a causa eleita deve estar em consonância com os anseios dos clientes e ser amplamente divulgada, trazendo assim melhores resultados para a construção da marca da empresa e de seus produtos. Sob o aspecto teórico, as informações obtidas demonstram que, quanto à realização dos programas de marketing social corporativo, o foco principal tem sido a comunidade no entorno da empresa e funcionários e não os clientes, diferentemente do que é apresentado na teoria.

A participação dos vários níveis empresariais nas atividades dos institutos e fundações demonstram a conscientização empresarial quanto à necessidade do envolvimento da empresa com um valor social e dos impactos positivos que esta ação pode causar na sociedade e nos clientes. No entanto, não foi identificada grande participação da comunidade ou dos familiares dos funcionários, demonstrando a inexistência ou pouca parceria da empresa, seu instituto ou fundação e a comunidade. Este aspecto reflete implicações, em especial para o empreendedorismo social. A teoria que está em desenvolvimento sobre o tema precisa ser ampliada buscando aspectos específicos das organizações do terceiro setor. No caso de fundações e institutos, principalmente fatores como riscos e a iniciativa e, ainda, ação coletiva, são minimizados em detrimento de características muito próprias deste tipo de organização: a possibilidade da iniciativa de criação destas organizações partir de outra organização, com fins lucrativos, e que preocupa-se com outros resultados, além dos benefícios sociais.

\section{Sugestões para pesquisas e novos estudos}

Várias possibilidades decorrem do estudo aqui apresentado. Algumas delas dizem respeito a: (i) pesquisas sobre resultados que podem ser alcançados com a ampliação e potencialização das práticas de marketing social corporativo no Brasil; (ii) pesquisas para explicar a escolha da causa para a atuação social empresarial focada na comunidade do entorno da empresa e não nas causas eleitas pelos clientes; (iii) pesquisas sobre o processo de criação de organizações do terceiro setor, de acordo com as especificidades de suas características e classificações legais; e (iv) pesquisas com foco no desenvolvimento de novas teorias de empreendedorismo social. 


\section{REFERÊNCIAS}

ALENCAR, E. Introdução à metodologia de pesquisa social. Lavras: UFLA, 1999.

ALVES-MAZZOTTI, A. J. ; GEWANDSZNAJDER, F. O método nas ciências naturais e sociais: pesquisa quantitativa e qualitativa. $2^{\mathrm{a}}$. ed. São Paulo: Pioneira, 1999.

ASHOKA E. S.; MCKINSEY; COMPANY. Empreendimentos sociais sustentáveis: como elaborar planos de negócio para organizações sociais. São Paulo: Peirópolis, 2001.

AUSTIN, J.; STEVENSON, H.; WEI-SKILLERN, J. Social and commercial entrepreneurship: same, different or both? Entrepreneurship Theory and Practice, v. 30, n.1, p. 2-22, jan. 2006.

BABBIE, E. Métodos de pesquisas de survey. Belo Horizonte: Ed. UFMG, 1999.

BECKER, H. S. Métodos de pesquisa em ciências sociais. São Paulo: HUCITEC, 1997.

CHELL, E. Social enterprise and entrepreneurship: Towards a convergent theory of the entrepreneurial process. International Small Business Journal, v. 25, n. 1, p. 5-26, 2007.

CORREA, P. S. A.; VIEIRA, F. G. D. A influência do marketing social corporativo na identidade corporativa das indústrias de alimentos do Paraná. In: EMA - ENCONTRO DE MARKETING. 3, 2008, Curitiba. Anais... Rio de Janeiro: ANPAD, 2008. 1 CD-ROM.

DEES, G. J. The meaning of "social entrepreneurship". Disponível em: http://www.fuqua.duke.edu/centers/case/documents/dees_SE.pdf . Texto original criado em 31 out 1998. Acesso em: 12 set. 2007.

DEGEN, R. O empreendedor: fundamentos da iniciativa empresarial. São Paulo: Pearson Education do Brasil, 1989.

DORNELAS, J. Empreendedorismo. Rio de Janeiro: Campus, 2001.

GARTNER, W.B. A conceptual framework for describing the phenomenon of new venture creation. Academy of Management Review, v. 10, n. 4, p. 696-706, 1985.

GIFE - GRUPO DE INSTITUTIOS, FUNDAÇÕES E EMPRESAS. Censo GIFE 2005/2006. São Paulo, 2006. Disponível em: <www.gife.org.br>. Acesso em: 05 fev. 2007.

GÜNTER, H. Como elaborar um questionário. Série Planejamento de pesquisa nas Ciências Sociais $n^{\circ}$ 1. Brasília, DF: UNB, 2003. Disponível em:

$<$ http://www.unb.br/ip/lpa/pdf/01Questionario.pdf $>$. Acesso em 05/01/2008.

HERNANDEZ, É. M. Le processus entrepreneurial: vers umn modèle stratégique d' entrepreneuriat. Paris: L' Harmattan, 1999. 
HIGUCHI, A. K.; VIEIRA, F. G. D. Responsabilidade social corporativa e marketing social corporativo: uma proposta de fronteira entre esses dois conceitos. In: ENANPAD ENCONTRO ANUAL DOS PROGRAMAS DE PÓS-GRADUAÇÃO EM ADMINISTRAÇÃO. 31, 2007, Rio de Janeiro. Anais... Rio de Janeiro: ANPAD, 2007. 1 CD-ROM.

HIGUCHI, A. K.; VIEIRA, F. G. D. Marketing social corporativo como estratégia para a valorização de marcas: um estudo da perspectiva do consumidor de alimentos do Paraná. Revista Alcance, v. 15, n. 2, p. 243-261, 2008.

KOTLER, P.; ZALTMAN, G. Social marketing: an approach to planned social change. Journal of Marketing, v. 35, n. 3, p. 3-12, jul. 1971.

KIRSTEN, J. T. Estatística para as ciências sociais: teoria e prática. São Paulo: Saraiva, 1980.

MALHOTRA, Naresh K. Pesquisa de marketing: uma orientação aplicada. 4a. ed. Porto Alegre: Bookman, 2006.

MANGIONE, T. Mail surveys. In: BICKMAN, Leonard e ROG, Debra J. (Orgs.) Handbook of Applied Social Research Methods. London: Sage, 1997.

MASSÓ, R. G. El benefício de compartir valores: marketing social corporativo, una nueva estrategia para diferenciar las marcas. Bilbao: Deusto, 1998.

MATTIELLO, K.; VIEIRA, F. G. D. Empreendedorismo social por meio de ações de marketing social corporativo: evidências da realidade brasileira. In: EGEPE - ENCONTRO DE ESTUDOS SOBRE EMPREENDEDORISMO E GESTÃO DE PEQUENAS EMPRESAS. 5. 2008, São Paulo. Anais... Maringá: PPA/UEM-UEL / PPA/UPM-SP, 2008, p. 1-12. 1 CD-ROM.

MELO NETO, F. P.; FROES, C. Empreendedorismo social: a transição para a sociedade sustentável. Rio de Janeiro: Qualitymark, 2002.

MORT, G. S; WEERAWARDENA, J.; CARNGIE, K. Social entrepreneurship: towards conceptualisations. International Journal of Nonprofit and Voluntary Sector, v. 8, n. 1. p. 76, fev. 2003.

OLIVEIRA, E. M. Empreendedorismo social no Brasil: atual configuração, perspectivas e desafios - notas introdutórias. Revista da FAE, v. 7, n. 2, p. 9-18, jul./dez. 2004.

OLIVEIRA, R. S. de. Marketing social corporativo nas indústrias do Paraná. 2006. 218 f. Dissertação (Mestrado) - Programa de Pós-Graduação em Administração, Universidade Estadual de Maringá e Universidade Estadual de Londrina, Maringá, 2006.

OZGEN, E.; BARON, R. A. Social sources of information in opportunity recognition: effects of mentors, industry networks, and professional forums. Journal of Business Venturing, $\mathrm{v}$. 22, n. 2, p. 174-192, 2006. 
PIMENTA, S. M.; SARAIVA, L. A. S.; CORRÊA, M. L. Terceiro setor: dilemas e polêmicas. São Paulo: Saraiva, 2006.

PRINGLE, H.; THOMPSON, M. Marketing social: marketing para causas sociais e a construção das marcas. São Paulo: Makron Books, 2000.

ROSSONI, L.; ONOZATO, E.; HOROCHOVSKI, R. R. O terceiro setor e o empreendedorismo social: explorando as particularidades da atividade empreendedora com finalidade social no Brasil. In: ENANPAD - ENCONTRO ANUAL DOS PROGRAMAS DE PÓS-GRADUAÇÃO EM ADMINISTRAÇÃO. 30, 2006, Salvador. Anais... Rio de Janeiro: ANPAD, 2006. 1 CD-ROM.

SALAZAR, J. N. A.; DORIZOTTO, C. M. Espaço empreendedor para parcerias entre as empresas de Piracicaba do setor metal-mecânico e as organizações do terceiro setor In: EGEPE - ENCONTRO DE ESTUDOS SOBRE EMPREENDEDORISMO E GESTÃO DE PEQUENAS EMPRESAS. 4. 2005, Curitiba. Anais... Maringá: PPA/UEM/UEL/PUC-PR, 2005, p. 348-359. 1 CD-ROM.

SELLTIZ, C.; WRIGHTSMAN, L. S.; COOK, S. W. Métodos de pesquisa nas relações sociais. São Paulo: E.P.U., 1975.

SCHROEDER , J. T.; SCHROEDER, I. Responsabilidade social corporativa: limites e possibilidades. RAE-eletrônica, v.3, n.1, jan./jun. 2004. Disponível em: $<$ www.rae.com.br/eletronica/index $>$.

SHANE, S.; VENKATARAMAN, S. The promise of entrepreneurship as a field of research. Academy of Management Review, v. 25, n. 1, p.217-226, jan. 2000.

SIEGEL, S. Estatística não-paramétrica para ciências do comportamento. $2^{\mathrm{a}}$ Ed. Porto Alegre: Artmed, 2006.

TREVISAN, F. A. Balanço social como instrumento de marketing. RAE Eletrônica, v.1, n.2, p. 1-12, 2002.

URDAN, A. T. Os consumidores recompensam o comportamento ético? Revista de Administração (RA-USP), São Paulo, v. 36, n. 2, p. 6-15, abr./jun. 2001.

VIEIRA, F. G. D.; HIGUCHI, A. K.; OLIVEIRA, R. S. de; CORREA, P. S. A. Marketing social corporativo: estado-da-arte e proposição de um modelo conceitual. In: ENANPAD ENCONTRO ANUAL DOS PROGRAMAS DE PÓS-GRADUAÇÃO EM ADMINISTRAÇÃO. 31, 2007, Rio de Janeiro. Anais... Rio de Janeiro: ANPAD, 2007. 1 CD-ROM. 